\title{
PEMBUATAN DAN PENGUJIAN MESIN PENYERUT TUSUK SATE MEKANIK
}

\author{
Gusri Akhyar Ibrahim*, Arinal Hamni, Margaretta Welly, Riki Andriyanto, Budi Harjo \\ ${ }^{1}$ Jurusan Teknik Mesin, Universitas Lampung, Bandar Lampung. \\ Jl. Prof. Sumantri Brojonegoro No.1 Bandar Lampung 35145 \\ Penulis Korespodensi : gusri.akhyar@eng.unila.ac.id
}

\begin{abstract}
Abstrak
Provinsi Lampung, daerah yang terletak di ujung pulau Sumatera memiliki potensi sumber daya alam yang melimpah, salah satunya adalah bamboo. Saat ini, bambo banyak dimanfaatkan untuk menghasilkan kerajinan-kerajinan berupa industry kreatif. Desa Sidomulyo adalah salah satu daerah di Lampung Selatan yang sebagian besar masyarakatnya mengolah bambu menjadi bahan untuk tusuk sate. Proses pembuatan tusuk sate yang dilakukan saat ini dengan mengunak peralatan yang dioperasikan secara manual, sederhana dan tanpa bantuan mesin. Proses pembuatan tusuk sate antaranya adalah pembelahan, peranjangan, peruncingan, penyerutan dan pemolesan. Salah satu tahap proses yang penting adalah penyerutan, dimana dilakukan menggunakan pisau penyerut, ditarik menggunakan tang. Proses ini memerlukan waktu yang lama sehingga kapasitas produksinya sedikit, sementara kebutuhan akan tusuk sate sangat banyak permintaanya. Oleh karena itu, untuk meningkatkan produktivitas tusuk sate diperlukan mesin penyerut mekanik yang dapat memproduksi tusuk sate yang lebih efisien dan lebih efektif. Efisien yang dimaksud yaitu hemat, cepat dan tenaga yang dikeluarkan untuk mengerjakan ini lebih sedikit. Sedangkan efektif disini yaitu untuk memaksimalkan tujuan yang diharapkan seperti memudahkan para pengerajin dalm membuat tusuk sate.Mesin tusuk sate dibuat menggunakan mesin setengah PK dengan untuk memutar puli dan puli disambungkan ke roda-roda yang berfungsi untuk menggerakan lidi menuju pisau serut. Setelah dilakukan pembuatan mesin penyerut tusuk sate mekanik, dapat meningkatkan produksi tusuk sate hingga mencapai $80 \%$ dari hasil penyerutan dengan menggunakan cara manual. Sehingga dengan demikian dapat meningkatkan pendapatan usaha dan memenuhi keperluan tusuk sate di daerah sekitarnya.
\end{abstract}

Kata kunci: Tusuk sate, penyerut, bambu, produksi, kapasitas.

\section{Pendahuluan}

Bambu adalah tanaman jenis rumputrumputan dengan rongga dan ruas dibatangnya. Bambu memiliki banyak tipe dan nama antarnya adalah buluh, aur, dan eru dan lain sebagainya. Di banyak tempat, bambu dianggap sebagai salah satu tanaman dengan pertumbuhan paling cepat, karena memiliki sistem rhizoma-dependen unik. Dalam sehari bambu dapat tumbuh panjang $60 \mathrm{~cm}$ (24 inchi) bahkan lebih, tergantung pada kondisi tanah dan klimitologi tempat ia ditanam [1].

Di Desa Sidomulyo Kabupaten Lampung Selatan, sebagian besar masyarakatnya mengolah pohon bambu untuk di jadikan tusuk sate. Pembinaan dilakukan di setiap rumah dengan cara memberikan pelatihan untuk membuat tusuk sate. Namun di dalam pembuatan tusuk sate ini masih dilakukan dengan secara manual, yaitu dengan menggunakan tenaga manusia dan alat penyerut yang sangat sederhana. Penyeritan dilakukan hanya menggunakan pisau penyerut dan tang yang digunakan sebagai penarik dari tusuk sate (Samadi, 2015),

Pembuatan tusuk sate di Desa Sidomulyo sangat sederhana karena semua di lakukan dengan manual. Dengan pengerjaaan yang manual seperti ini maka hasil yang di dapatkan untuk tusuk sate sangat lama. Tidak hanya itu ketika kita menggunakan pengerjaan yang manual maka kualitas hasil dari tusuk sate tidak baik, banyak serabut, tidak seragam dan tidak menarik. Ini dikarenakan ketika proses penyerutan tusuk sate, masyarakat hanya 
menggunakan alat yang sangat sederhana sekali. Jadi ketika tusuk sate akan diserut maka kebulatan penampang tusuk sate tidak sama rata. Sedangkan ketebalan diameternya tusuk sate ini yang dibuat antara 2,5 - 3 milimeter, namun pada kenyataannya hasil yang diperoleh untuk diameter tusuk sate tidak sesuai dengan permintaan pasar. Tidak hanya itu, kekurangan yang ditemukan, bila menggunakn mesin penyerut manual kontruksi yang digunakan kurang nyaman karena ketika melakukan penyerutan tusuk sate harus dengan menghasilkan sisa sampah penyerutan yang banyak. Hasil produksi ini disebabkan oleh proses awal pengerjaan penyerutan tusuk sate tidak sama rata ukurannya. Dengan banyaknya permintaan pasar terhadap tusuk sate tersebut seringkali permintaan tusuk sate yang sangat banyak tidak bisa dipenuhi, di karenakan di dalam pembuatannya masih menggunakan metode manual, yang membutuhkan waktu dan tenaga yang banyak. Tidak hanya waktu dan tenaga yang sangat lama pengerjaan tetapi harga produksi juga akan meningkat sehingga akan mengurangi hasil dari penjualan tusuk sate. Dari semua proses pembuatan tusuk sate tersebut yang membutuhkan waktu yang banyak adalah pada saat melakukan proses penyerutan, selain membutuhkan tenaga yang banyak, juga membutuhkan waktu yang sangat lama untuk menyelesaikan 1 kilo gram tusuk sate.

Dari permasalahan yang dihadapi demikian, maka solusi yang dapat dilakukan adalah tindakan inovasi melalui kegiatan merancang suatu alat bantu untuk menyerut tusuk sate. Alat ini beroperasi secara semi otomatis yang mampu mempercepat pembuatan tusuk sate di desa sidomulyo lampung selatan. Sehingga dapat meningkatkan produktivitas ekonomi perajin tusuk sate skala home industry di Desa Sidomulyo Lampung Selatan. Oleh karena itu perlu dilakuka inovasi pembuatan dan sekaligus pengujian mesin tusuk sate. Dimana alat ini digunakan untuk membantu mempercepat proses pembuatan tusuk sate di desa sidomulyo, sehingga kebutuhan akan permintaan tusuk sate dapat terpenuhi. Kemudian di dalam laporan ini juga di jelaskan konstruksi, prinsip kerja,dan proses pembuatan alat.

Metode pelaksanaan kegiatan yang dilakukan adalah dengan melakukan beberapa tahapan, diawali dengan survey kebutuhan hingga menghasilkan produk yang dibutuhkan oleh pengerajin tusuk sate. Secara detail metode dan tahapan kegiatan ini adalah sebagai berikut: (1) sosialisasi program dan observasi di lapang tentang keadaan sebenarnya (existing condition) pengrerajin tusuk sate mitra yang akan dikembangkan, (2) disain (design) alat penyerut tusuk sate mekanik yang lebih efisien dan efektif. (3) pembuatan alat penyerut tusuk sate dengan kapasitas penyerutan satu menit dapat menghasilkan 50 tusuk sate. (4) uji performan (test performance) alat penyerut tusuk sate mekanik dengan menggunakan motor bensin dan Uji kwalitas tusuk sate dengan melihat penampang geometri lingkaran menggunakan jangka sorong ataupun dengan menggunakan micrometer.

Disain alat penyerut tusuk sate mekanik ini diakukan menggunakan software solid work. Tahap disain dilaksana dengan metode pembuatan komponen alat secara satu persatu, yang kemudian dirakit menj adi gambar utuh. Proses manukfaktur dilakukan di laboratorium proses produksi Jurusan Teknik Mesin Universitas Lampung. Pengujian tahap awal dilakukan di Laboratorium, dan selanjutkan pengujian secara lengkap dilaksanakan di lokasi industri mitra, yakni di desa Krajan , Kecamatan Sidomulyo, Kabupaten Lampung Selatan. Pengambilan data dan uji performansi alat yang dibuat dilakukan menggunakan bamboo yang sudah di belah dengan menggunakan golok baik kondisi bambu masih basah ataupun sudah kering.

Penyerut tusuk sate mekanik ini dibuat menggunakan plat siku yang berfungsi untuk membuat rangka penyerut tusuk sate. Kemudian penggerak untuk menggerakan mesin penyerut tusuk sate ini menggunak mesin bensin dengan kapasitas 6,5 pk. Dengan 
kapasitas sebesar ini maka mesin mampu menggerakan poros atau shaf yang memutarkan roller untuk menghimpit bambu yang akan diserut oleh plat penyerut tusuk sate yang sipasangkan diantara roller roler karet. Plat penyerut sendiri ini memiliki 3 buah lubang dengan ukuran yang berbeda. Tujuan dubuat 3 buah lubang ini adalah ketika mata penyerut tusuk sate sudah mengalami kauasan yang disebabkan penggunaan yang terus menerus maka plat penyerut dapat digeser atau di pindahkan di lubang selanjutnya dengan menggunakan pengatur plat penyerut yang terpasang. sehingga hanya dengan memposisikan plat penyerut dengan posisi center maka posisi lubang pada penyerut sudah bisa digunakan kembali untuk proses penyerutan. Plat penyerut tusuk sate ini ibuat dengan perlakuan panas sehingga plat penyerut lebih tajam ketika dipakai dan umur pakai lebih lama.

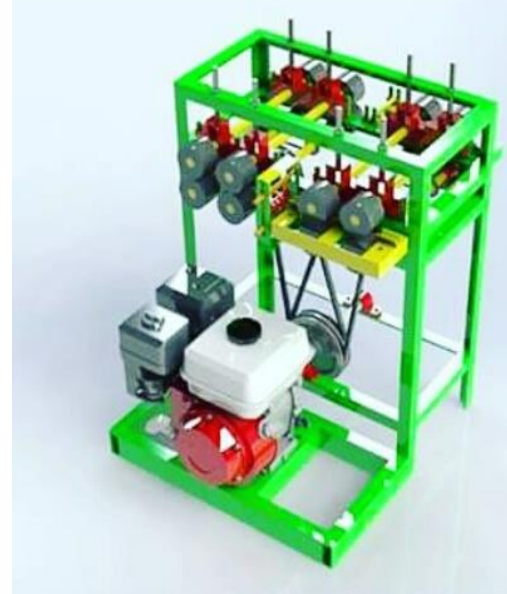

Gambar 1. Rancangan alat penyerut tusuk sate mekanik.

\section{Hasil}

Dalam mendesain Mesin Penyerut Tusuk Sate ini dibuat untuk digunakan dalam mengatasi masalah peningkatan produktivitas hasil produksi dari pembuatan tusuk sate. Selama ini proses pembuatan tusuk sate hanya dilakukan dengan menggunakan cara yang sanggat sederhana yaitu hanya dengan menggunakan penyerut manual. Dengan menggunakan cara seperti ini tentunya sangat memakan waktu dan membutuhkan tenaga yang banyak.

Karena itu dibuat alat atau mesin penyerut tusuk sate secara mekanis dengan menggunkan mesin yang bertujuaan untuk memudahkan para pengerajin tusuk sate untuk membuat tusuk sate sehingga akan meminimalisir waktu dan tenaga yang dibutuhkan. Metode yang di gunakan dalam pembuatan mesin penyerut tusuk sate ini adalah metode tepat guna, selain memudahkan pengerajin tusuk sate alat penyerut tusuk sate ini juga efisien, dimana didalam proses pembuatan alat tersebut menggunakan material yang mudah di cari baik dalam jumlah ataupun dalam segi harga yang sangat ekonomis.

Dalam proses pembuatan mesin tusuk sate yang pertama kita persiapkan adalah menyiapkan bahan-bahan yang akan kita gunakan untuk membuat komponen dan rangka. Setelah semua bahan disiapkan, maka pertama kita harus melakukan pengukuran. Pengukuran ini mencakup seluruh komponen atau rangka yang akan dibuat. Setelah semua bagian diukur maka selanjutnya dilakukan proses pemotongan bahan, setelah selesai pemotongan bahan yang akan dibuat maka selanjutnya dari bahan yang sudah dipotong tersebut kita sambung dengan menggunakan mesin las. Sehingga dari sambungan itu akan terbentuk komponen seperti rangka mesin penyerut tusuk sate. Pada rangka ini sendiri memiliki ukuran panjang $600 \mathrm{~mm}$, lebar 300 $\mathrm{mm}$, tinggi rangka $750 \mathrm{~mm}$.setelah itu ukuran untuk penyearah sendiri memiliki ukuran panjang $249 \mathrm{~mm}$, dan lebar $106 \mathrm{~mm}$.dan untuk ukuran penyerut tusuk sate sendiri memiliki perbedaan ukuran lubang pada setiap lubangnya, untuk lubang penyerut 1 ukuranya, $2 \mathrm{~mm}$, kemudian lubang 2 ukuranya, $3 \mathrm{~mm}$ dan lubang terakhir lubang ke 3 memiliki ukuran 5 $\mathrm{mm}$. Dan ukuran untuk penyetel penyerut tusuk sate memiliki panjang $140 \mathrm{~mm}$ dan lebar $50 \mathrm{~mm}$. Setelah itu alat ini juga memiliki poros dengan panjang $460 \mathrm{~mm}$ dan diameter $20 \mathrm{~mm}$. Selanjutnya diujung poros terdapat roller karet ada 16 roller karet dengan ukuran diameter luar $70 \mathrm{~mm}$ dan diameter dalam $20 \mathrm{~mm}$. 


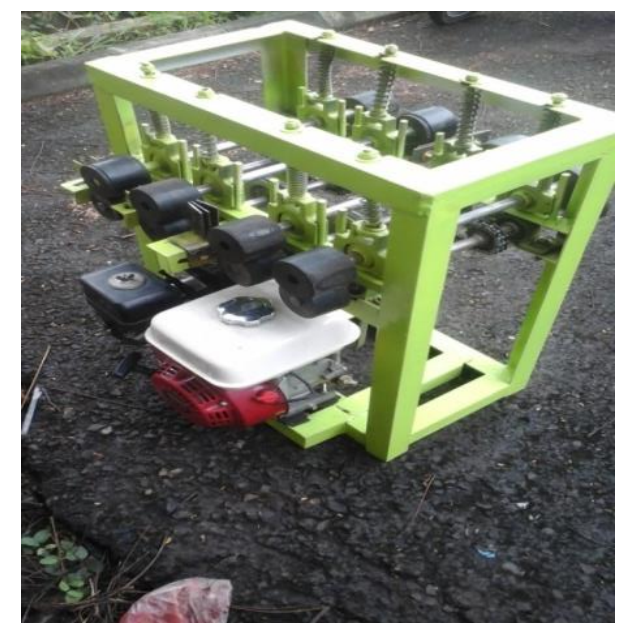

Gambar 2. Alat penyerut tusuk sate. Spesifikasi mesin penyerut tusuk sate.

1. Panjang $=600 \mathrm{~mm}$

2. Lebar $=300 \mathrm{~mm}$

3. Tinggi $=750 \mathrm{~mm}$

4. Diameter penyerut $=\mathrm{D} 1,2 \mathrm{~mm} \mathrm{D} 2,3 \mathrm{~mm}$ D3, $5 \mathrm{~mm}$

5. Jumlah penyerut $=1$ buah dengan 3 lubang

6. Daya motor $=6,5 \mathrm{hp}$

7. Kapasitas $=50$ tusuk sate $/ \mathrm{mnt}$

Untuk mengoperasikan mesin penyerut tusuk sate ini ada beberapa hal yang harus di perhatikan untuk cara kerja alat sebagai berikut:

1. Siapkan tusuk sate yang akan diserut .

2. Hidupkan motor bensin untuk memutarkan roller

3. Letakkan bagian ujung batang tusuk Sate ke penyearah yang berdekatan dengan roller yang telah berputar.

4. Masukkan batang tusuk sate setelah itu penyerut akan menyerut batang tusuk sate .

5. Setelah itu keluar hasil tusuk sate dengan bergeometri penampang lingkaran dan memiliki ukuran panjang $44 \mathrm{~cm}$.

Setelah semua prosedur dilakukan dengan baik dan benar, maka proses pengujian alat dilakukan dengan cara menghidupkan motor bensin. Tetapi sebelum melakukan sebaiknya diperiksa terlebih dahulu dari motor bensin seperti bahan bakar, pastikan sudah terisi dan setelah itu periksa kelayakan dari pully dan $\mathrm{v}$ belt ini dilakukan untul memeriksa kekencangan tali v beltnya. Stelah itu periksa pisau penyerut tusuk sate sudah terpasang sengan sempurna apa belum, ketika pisau penyerut tusuk sate belum terpasang dengan sempurna maka bisa disetel atau diatur dengan menggunakan pengatur pisau penyerut yang berada di bawah pisau penyerut. Setelah semua dalam kondisi baik dan sudah siap untuk dilakukan pengujian maka motor bensin dihidupkan dan kemudian batang bambu yang akan diserut di letakan di penyearah. Setelah diletakan di depan penyearah maka tusuk sate langsung dimasukan dan di tarik dengan roller dan melewati pisau penyerut tusuk sate. Kemudian setelah itu tusuk sate akan keluar dan memiliki hasil ukuran diameter dari tusuk sate 2,5 mm. Dan dalam satu menit putaran mesin penyerut tusuk sate menghasilkan 50 batang tusuk sate.

Berikut ini adalah cara proses pengoperasian dari mesin penyerut tusuk sate :

1. Menyiapakan bambu yang di belah kecilkecil dengan ukuran $440 \mathrm{~mm}$. Kemudian setelah bambu di belah kecil- kecil debersihkan agar tidak melukai tangan ketika akan dilakukan penyerutan .setelah itu bambu itu di letakan ditempat atau wadah agar besi terkumpul dan menjadi satu di satu tempat. Dalam pembelahan bambu jangan terlalu besar atau terlalu kecil ini dikarenakan akan mempengaruhi hasil dari kualitas dan juga akan mempengaruhi proses dari penyerutan tusuk sate itu sendiri. Dan ketika memasukan bambu di roller harus diberi jeda jangan terlalu cepat dan terlalu lambat. Ketika terlalu cepat di takutkan akan mengalami slip pada proses penyerutan. Dan ketika terlalu lama maka akan mempengaruhi hasil dari jumlah tusuk sate itu sendiri. Adapun hasil pembelahan bambu yang akan diserut dapat dilihat pada gambar 3 . 


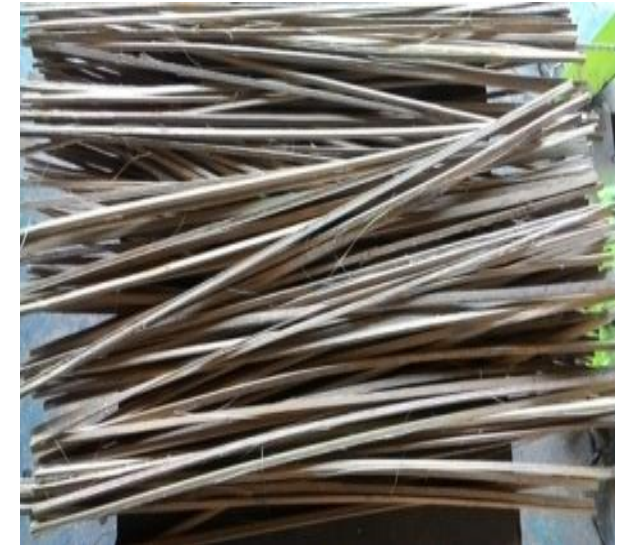

Gambar 3. Bambu yang akan diserut.

2. Kemudian menghidupkan mesin atau motor penyerut. Tetapi yang perlu diperhatikan sebelum meghidupkan mesin adalah memeriksa bahan bakar apakah sudah terisi penuh atau bahkan tidak terisi bahan bakar. Setlah itu periksa kekencangan pully dan $\mathrm{v}$ belt, jangan sampai ketika menghidupkan mesin pully dan $\mathrm{v}$ belt dalam kondisi tidak kencang, karena akan berdampak pada rusaknya alat penyerut tusuk sate . setelah itu pastikan pisau penyerut tusuk sate kondisi siap pakai dan sejajar dengan penyearah agar tusuk sate dapt keluar dari roller dengan hasil yang baik. Setelah semua kondisi baik maka motor dihidupkan, adapun cara menghidupkan motor dapat dilihat pada gambar 4.

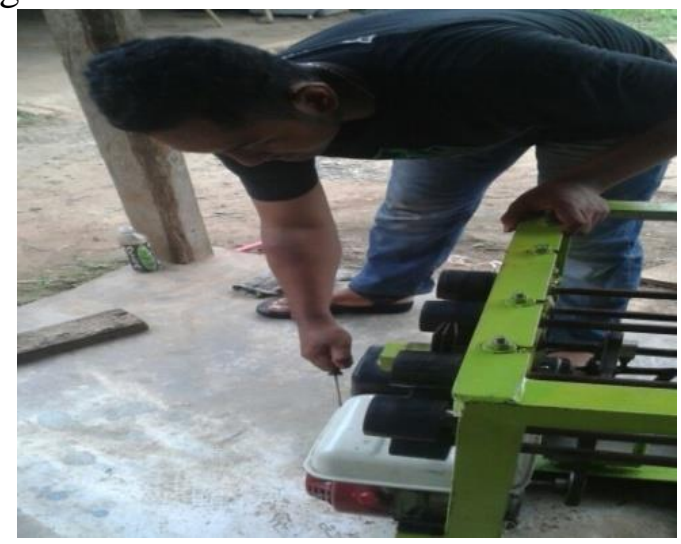

Gambar 4. Menghidupkan motor penggerak.

3. Ketika mesin sudah hidup dan putaran mesin sudah pada kondisi stasioner. Maka masukan bambu yang akan di serut ke penyearah setelah itu bambu yang dimasukan akan terbawa oleh putaran roller dan kemudian putaran ini akan membawa tusuk sate kedepan pisau penyerut. Setelah itu bambu masuk dan diserut oleh pisau penyerut dan keluar dari pisau penyerut melalui roller karet lagi dan keluar sudah dengan hasil yang sudah terserut sesuai dengan diameter lubang yang terpasang pasang pada pisau penyerut.

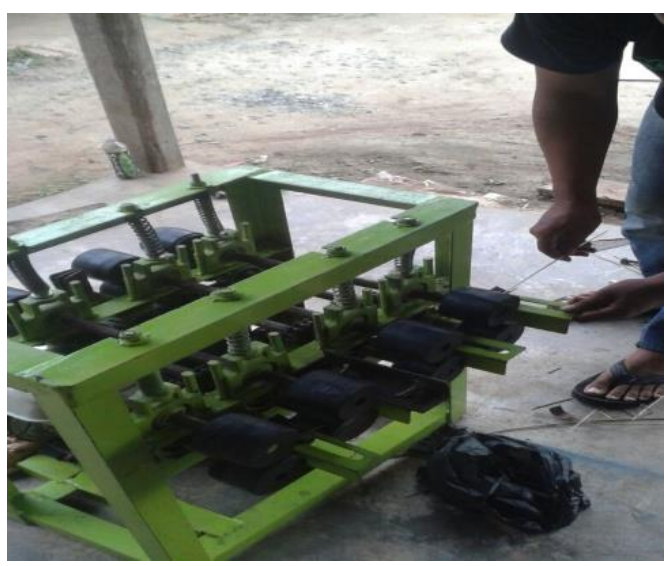

Gambar 5. Memasukan bambu ke roller.

4. Hasil serutan akan keluar dengan ukuran panjang $440 \mathrm{~mm}$

5. Setelah itu didapatkan hasil pengujian. Adapun hasil pengujian dapat dilihat pada gamabr 6.

berikut adalah hasil pengujian tusuk sate dengan manual dan mesin secara mekanik.

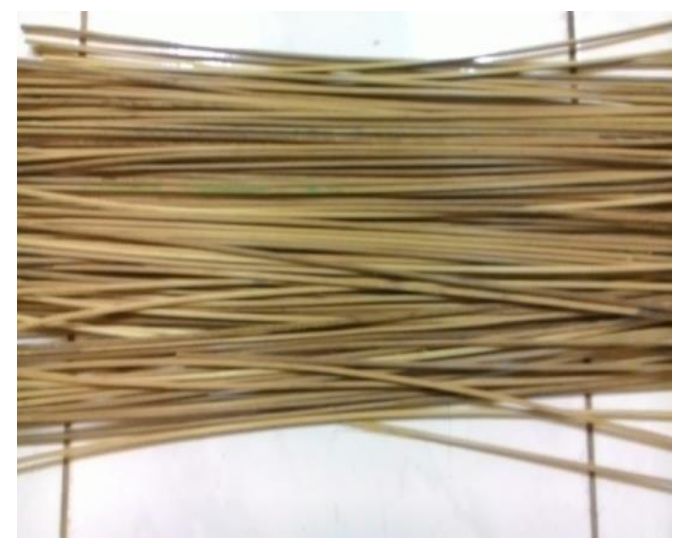

Gambar 6. Hasil penyerutan dengan mesin serut mekanik 


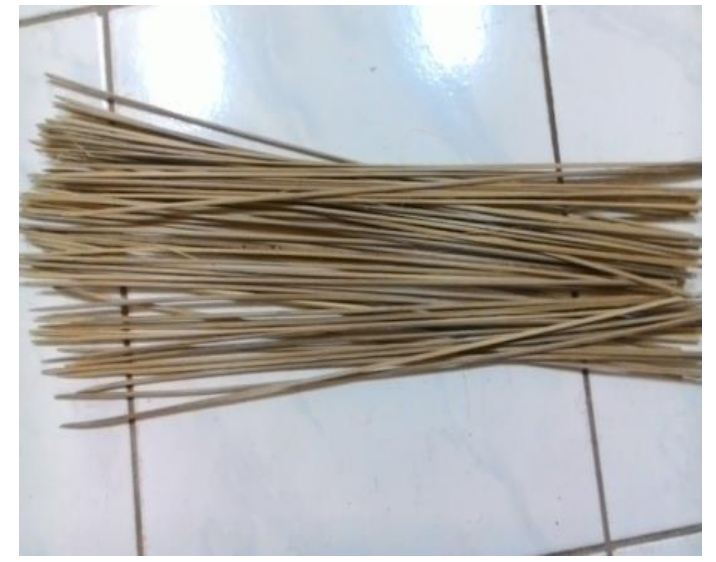

Gambar 7. Hasil penyerutan secara manual.

Dari hasil pengujian diatas dapat di simpulkan bahwa dengan menggunakan mesin penyerut tusuk sate hasil yang didapatkan lebih baik kualitas dari tusuk sate lebih bergeometri penampang lingkaran dibandingkan dengan menyerut secara manual. Hasil manual kurang bersih pada tusuk satenya dan kebulatan dari tusuk sate tidak sama ada yang kekicilan, pipih dan bahkan tidak bulat. Ini diakibtkan karena saat menyerut tidak sama ukurannya. Tidak hanya itu ketika menggunakan mesin penyerut tusuk sate ini secara mekanik maka waktu yang dibutuhkan sangat singkat satu kali proses hanya membutuhkan waktu 1 detik untuk satu tusuk sate. Sedangkan dengan manula waktu yang dibutuhkan lebih besar dan tenaga lebih besar juga satu kali proses membutuhkan waktu sebesar 5 detik. Dan ketika akan melakukan penyerutan ujung dari bambu harus di runcingkan terlebih dahulu agar bisa masuk ke penyerut. Sehingga ini akan memakan waktu yang lama juga. Dan tidak hanya itu ketika akan melakukan penyerutan secara manual opertor harus menarik batang bambu yang akan diserut dengan mengunakan tang satu persatu sehingga membutuhkan waktu yang lama lagi di bandingkan dengan menggunakan penyerut secara mekanik.

Adapun perbandingan hasil pengujian

Data dapat di peroleh dengan menggunakan perhitungan sebagai berikut:

Proses manual

Kecepatan kerja $= \pm 10$ tusuk sate $/$ menit
Jadi jika dengan menggunakan waktu kerja yang sama:

10 menit $=\ldots \ldots$.

Jumlah 10 menit $=$ vk $\times 10$ menit

$=10$ ts $/$ menit $\times 10$ menit

$=100$ tusuk sate

Jadi dalam 10 menit kerja secara manual dapat di peroleh hasil penyerutan sebanyak 100 tusuk sate.

Jumlah kerja 1 jam $=(60$ menit $)$

$=\mathrm{vk} \times 60$ menit

$=10$ ts/menit $\times 60$ menit

$=600$ tusuk sate.

Jadi dengan waktu satu jam hasil yang di peroleh penyerutan tusuk sate secara manual adalah sebanyak 600 tusuk sate.

Proses mekanik

1 menit $=50$ tusuk sate

Jadi kecepatan produksi mesin $(\mathrm{vk})=50$ ts/menit

Waktu kerja 10 menit

Jumlah 10 menit $=$ vk $\times 10$ menit

$=50$ ts/menit $\times 10$ menit

$=500$ Tusuk sate

Jadi dalam 10 menit penyerutan dengan menggunakan mesin serut tusuk sate secara mekanik di dapatkan hasil 500 tusuk sate.

Waktu kerja 1 jam

Jumlah kerja 1 jam = vk x 60 menit

$=50$ ts $/$ menit $\times 60$ menit

$=3000$ tusuk sate

Jadi dalam satu jam di dapatkan hasil tusuk sate sebanyak 3000 tusuk sate.

\section{Penutup}

Dari hasil pembuatan mesin penyerut tusuk sate ini dapat meningkatkan produksi pembuatan tusuk sate yang besar dan menghasilkan tusuk sate dengan kualitas dan produktifitas yang lebih baik. Bahan yang digunakan pada pembuatan mesin penyerut tusuk sate ini yaitu besi siku digunakan pada pembuatan rangka dan cekam, besi as pada pembuatan tongkat pengerolan karet, 3 lubang penyerut tusuk sate, serta motor 
bensin sebagai penggerak dari mesin penyerut tusuk sate Dari hasil pengujian juga didapat bahwa mesin penyerut tusuk sate ini lebih efektif dan efisien serta hasil serutan lebih bagus. Dari hasil pengujian di dapatkan dalam satu menit mesin penyerut tusuk sate bekerja menghasilkan 50 tusuk sate.

\section{Ucapan Terima Kasih}

Penulis mengucapkan banyak terima kasih kepada seluruh pihak yang sudah membatu untuk menyelesaikan templet ini. Semoga templet ini dapat bermanfaat dan berguna untuk semua lapisan masyarakat.

\section{Daftar Pustaka}

Basri, E. 1997, Pedoman Teknis Pengeringan Bambu . Laporan Proyek Penelitian dan Pengembangan Kehutanan Pusat. Pusat
Penelitian Hasil Hutan dan Sosial Ekonomi Kehutanan. Bogor.

F bastiar . 2015. Pengertian poros beserta jenis-jenisnya dapat diunduh pada http://fbastiar.blogspot.co.id/2015/09/pengerti an-poros-beserta-jenis-jenisnya.html

Nikball . 2015. Rubber roll. Dapat diunduh pada www.nikball.com.2015.03.ruber roll . html

Sutiyono. 2005. Menanam bambu untuk bahan bangunan. Prosiding Seminar Nasional Perkembangan Perbambuan di Indonesia. Pusat Studi Ilmu teknik, UGM, Yogyakarta. hal. II.53-II.62.

Zend juandy. 2013 pengertian dan spesifikasi bearing elemen mesin dapat diunduh padahttps://zend28juandy.wordpress.com/tag/ pengertian-dan-spesifikasi-bearing-elemenmesin-. 